\title{
ВЛИЯНИЕ ФИНАНСОВОЙ УСТОЙЧИВОСТИ ЭКОНОМИЧЕСКОГО СУБЪЕКТА НА ПРИВЛЕЧЕНИЕ ЗАЕМНОГО КАПИТАЛА
}

\author{
() 2021 Арефьев Игорь Игоревич \\ магистрант кафедры оценки бизнеса, учета и корпоративных финансов \\ Московский государственный университет технологий и управления имени К. Г. Разумовского \\ (ПКУ), Россия, Москва \\ E-mail: igarefa25@yandex.ru

\section{(C) 2021 Сурай Наталья Михайловна} \\ к.т.н., доцент, доцент кафедры оценки бизнеса, учета и корпоративных финансов \\ Московский государственный университет технологий и управления имени К. Г. Разумовского \\ (ПКУ), Россия, Москва
}

Актуальность темы исследования обусловлена необходимостью изучения проблем достижения финансовой стабильности через использование механизма управления структурой капитала. Целью исследования является обоснование предложений по актуальности оценки финансовой устойчивости для заинтересованных пользователей. В качестве методологической базы использован исторический подход с применением общих методов анализа, синтеза и аналогий. Рассмотрены методики оценки финансовой устойчивости на основе системы коэффициентов, сделаны выводы о влиянии заемного капитала на показатели финансовой устойчивости экономического субъекта. Анализ показателей финансовой устойчивости позволяет решить финансовые проблемы, определить уровень потребности в кредитных ресурсах, направляемых на развитие бизнеса.

Ключевые слова: финансовое состояние; финансовая устойчивость; источники формирования активов; заемные средства; кредитоспособность.

Функционирование экономических субъектов в условиях жесткой конкуренции и продолжающего кризиса неизбежно приводит к поиску источников финансирования хозяйственной деятельности. Одновременно, заинтересованные пользователи и стейкхолдеры уделяют повышенное внимание показателям, характеризующим эффективность использования финансовых ресурсов коммерческих организаций в краткосрочной и долгосрочной перспективе. Данную потребность, в большей степени, обеспечивает проведение финансового анализа, который позволяет оценить финансовое состояние организации по совокупности показателей ликвидности и платежеспособности, деловой активности, финансовой устойчивости и вероятностью наступления банкротства, основанного на данных бухгалтерской (финансовой) отчётности экономического субъекта.

Наиболее полное представление о финансовом состоянии раскрывают показатели финансовой устойчивости, отражающие соотношение активов и источников их формирования. Нередко высокие показатели ликвидности не являются подтверждением хорошего финансового со- стояния, а свидетельствуют о нерациональном распределении имеющихся финансовых ресурсов и не достаточно оптимальной структуре капитала. Выявить причины и факторы, негативно влияющие на эффективность управления финансовыми ресурсами экономического субъекта, позволяет анализ финансовой устойчивости. Показатели финансовой устойчивости разнородны и многофакторны. На показатели финансовой устойчивости влияет экономическое окружение, внутренняя и внешняя среда функционирования коммерческого предприятия.

Российские авторы дают понятие финансовой устойчивости. По мнению А.Д.Шеремета «финансовая устойчивость - это способность организации поддерживать свое существование и бесперебойную работу, благодаря наличию определенных свободных средств и сбалансированности финансовых потоков». Под финансовой устойчивостью М.Е.Гребнева понимает «один из главных показателей, дающий общее представление о состоянии дел в организации, о ее платежеспособности, финансовой дисциплине, стабильности деятельности, зависимости от кредитов и займов». По мнению О.И.Вяткиной 
«финансовая устойчивость предприятия (организации) предполагает такое состояние его ресурсов, которое обеспечивает развитие на основе роста прибыли и капитала при сохранении платежеспособности и кредитоспособности в условиях допустимого уровня риска». Многие авторы выделяют подход к определению понятия финансовой устойчивости М.М. Озиевой, которая считает, что «финансовая устойчивость хозяйствующего субъекта это такое состояние его денежных ресурсов, обеспечивающее развитие и совершенствование предприятия главным образом благодаря собственным средствам сохраняя платежеспособность и кредитоспособность при наименьшем уровне предпринимательского риска» [4, с. 128-132].

Разнообразие подходов к определению финансовой устойчивости подтверждает, что наряду с показателями, характеризующими ликвидность баланса, оборачиваемости активов и капитала и прочее, показатели финансовой устойчивости являются одними из существенных показателей, характеризующими финансовое состояние экономического субъекта.

В современной Российской практике анализ финансовой устойчивости проводят по абсолютным показателям, характеризующим финансовые запасы компании и источники их финансирования и относительным показателям, основанным на оценке финансовой независимости, финансового рычага, обеспеченности собственными средствами и рядом других показателей деятельности экономического субъекта. Важно, чтобы имеющиеся враспоряжении источники отвечали стратегии развития компании, в противном случае при низкой финансовой устойчивости предприятие будет не в состоянии выполнить свои обязательства перед контрагентами и государством, а слишком высокие показатели будут свидетельствовать об излишних запасах и затратах. Отсюда, финансовая устойчивость экономического субъекта обуславливается оптимальным соотношением запасов и расходованием денежных ресурсов для осуществления его текущей и инвестиционной деятельности [2, с. 68-70].

Российские авторысходятся во мнении, что анализ финансовой устойчивости следует начинать с описания состава и структуры активов и источников их формирования. Данный подход основан на том, что на начальном этапе анализа основных форм бухгалтерской (финансо- вой) отчётности должна быть дана оценка рациональности размера собственных и заемных источников, используемых при формировании активов компании. Далее проводят анализ обеспеченности запасов исходя из источников их финансирования, исходя из этого определяется платежеспособность или неплатежеспособность экономического субъекта. На следующем этапе проводится анализ относительных показателей на основе системы коэффициентов, позволяющих в динамике оценить способность предприятия развиваться за счет собственных источников. При этом компания должна иметь возможность привлекать заемные средства, то есть быть кредитоспособной для обеспечения гибкой структуры финансовых ресурсов.

Анализ финансовой устойчивости может быть проведен по системе коэффициентов - относительных показателей финансовой устойчивости:

$\mathrm{Ka}=\mathrm{CK} / \mathrm{A}$,

где: Ка - коэффициент автономии (независимости); СК - собственный капитал; А - активы. Нормативное значение 0,5-0,7.

Кфз $=($ ДО + КО $-3 \mathrm{y}+$ Дбп $+\mathrm{P}) /$ П,

где: Кфз - Коэффициент финансовой зависимости; ДО - долгосрочные обязательства; КО - краткосрочные обязательства; Зу - задолженность перед учредителями; Дбп - доходы будущих периодов; Р - резервы предстоящих расходов; П - пассивы. Нормативное значение: меньше 0,8 , оптимальное значение 0,5

$\mathrm{K} 3 \mathrm{C}=3 \mathrm{~K} / \mathrm{CK}$,

где: Кзс - коэффициент соотношения заемных и собственных средств; 3К - заемный капитал. Нормативное значение 0,5-0,7.

$\mathrm{KM}=\mathrm{COC} / \mathrm{CK}$,

где: Км - коэффициент маневренности собственного капитала; СОC - собственные оборотные средства. Нормативное значение $0,2-0,5$.

Км/ $/$ = ОА $/$ ВОА,

где: Км/и - коэффициент соотношения мобильных и иммобилизованных активов; ОА оборотные активы; BОА - внеоборотные активы.

$\mathrm{Ko}=\mathrm{COC} / \mathrm{OA}$,

Ко - коэффициент обеспеченности оборотного капитала собственными источниками финансирования. Нормативное значение $\geqslant 0,1$.

Коз $=$ СOC $/$ ЗАП,

где: Коз - коэффициент обеспеченности запасов собственными средствами; ЗАП - запасы. Нормативное значение 0,6-0,8. 
$\mathrm{KcKc}=\mathrm{CK \kappa} / \mathrm{CKH}$,

где: Кскс - коэффициент сохранности собственного капитала; СКк - собственный капитал на конец периода; СКн - собственный капитал на начало периода. Нормативное значение > 1 .

Своевременная и регулярная оценка финансового состояния, и в частности проведение анализа финансовой устойчивости является основным условием благополучия экономического субъекта. Источниками информации являются данные бухгалтерской (финансовой) отчётности.

В настоящее время кредит - одна из основных форм привлечения финансовых ресурсов в компанию для обеспечения непрерывной финансово-хозяйственной деятельности. Привлечение кредитов банков коммерческими предприятиями вызвано потребностью, с одной стороны, решить финансовые проблемы, с другой, потребность в кредитных ресурсах свойственна растущему бизнесу, ориентированному на инвестиционную деятельность. Оценив показатели, характеризующие уровень финансовой устойчивости, руководство экономического субъекта получит возможность определить потребность в привлечении банковского кредита для осуществления процесса расширенного воспроизводства.

Рассматривая привлечение банковских кредитов необходимо учитывать, что уровень рентабельности, в том числе планируемый в ходе осуществления инвестиционной деятельности должен быть не ниже средневзвешенной годовой ставки по кредитному портфелю. В противном случае привлечение заемных источников финансирования нецелесообразно.По данным
Банка России средневзвешенные годовые ставки по портфелю 2019-2020 годы по состоянию на 1 января 2021 года показали рекордное снижение и составили для юридических лиц по кредитам до 1 года 8,23\% годовых, свыше 1 года 7,49\% годовых при ключевой ставке Банка России $4,25 \%$ (рис. 1) [1].

Отсюда следует, что на сегодняшний день уровень рентабельности деятельности экономического субъекта не должен быть ниже 9\%. По состоянию на 04.06.2020 года, рентабельность проданных товаров, продукции, работ, услуг и рентабельность активов организаций по видам экономической деятельности составила $11,4 \%$, рентабельность активов 6,8\% [3].

В 2020 году около 41\% зарегистрированных юридических лиц и $20 \%$ индивидуальных предпринимателей привлекли кредитные ресурсы (табл. 1). В 2020 году количество юридических лиц и индивидуальных предпринимателей, получивших кредит, увеличилось на 63,65\%, теп прироста обращения за кредитными ресурсами практически одинаковый: 60,69\% у юридических лиц и 68,55\% у индивидуальных предпринимателей. В среднем, количество обращений за кредитами более одного раза. Полагаем, пандемия 2020 года отразилась на объемах кредитования. Кредитными организациями в 2020 г. на 12,01 млн. руб. выдано кредитов меньше, чем в 2019 году, темп снижения объемов кредитов, приходящихся на 1 юридическое лицо и индивидуального предпринимателя составил $26,95 \%$, несмотря на это общий кредитный портфель вырос на 19,55\% [1].

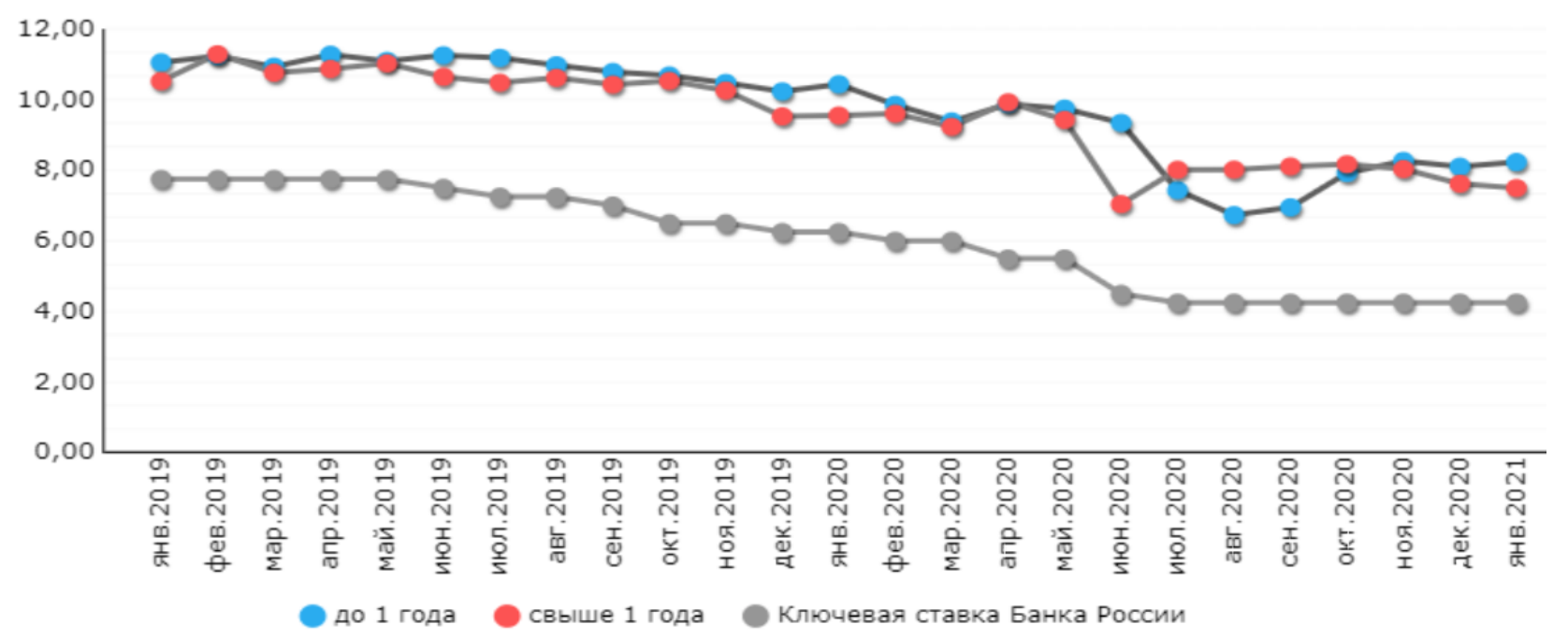

Рисунок 1. Динамика средневзвешенных процентных ставок за 2019-2020 годы, \% 
Таблица 1. Количество кредитов, предоставленных юридическим лицам - резидентам и индивидуальным предпринимателям в отчётном месяце, ед.

\begin{tabular}{|c|c|c|c|c|}
\hline Показатель & 2019 г. & 2020 г. & $\begin{array}{l}\text { Изменения, } \\
+/-\end{array}$ & $\begin{array}{l}\text { Темп изме- } \\
\text { нения, \% }\end{array}$ \\
\hline $\begin{array}{l}\text { Количество юридических лиц и индивидуальных } \\
\text { предпринимателей получивших кредит - всего, } \\
\text { ед. }\end{array}$ & 1154007 & 1888479 & 734472 & 163,65 \\
\hline \multicolumn{5}{|l|}{ в том числе: } \\
\hline юридические лица & 719896 & 1156797 & 436901 & 160,69 \\
\hline индивидуальные предприниматели & 434111 & 731682 & 297571 & 168,55 \\
\hline $\begin{array}{l}\text { Количество кредитов, предоставленных юриди- } \\
\text { ческим лицам и индивидуальным предпринима- } \\
\text { телям - всего, ед. }\end{array}$ & 1383557 & 2210624 & 827067 & 159,78 \\
\hline \multicolumn{5}{|l|}{ в том числе: } \\
\hline юридические лица & 915971 & 1414567 & 498596 & 154,43 \\
\hline индивидуальные предприниматели & 467586 & 796057 & 328471 & 170,25 \\
\hline $\begin{array}{l}\text { Объем кредитов, предоставленных юридическим } \\
\text { лицам и индивидуальным предпринимателям, } \\
\text { млн. руб. }\end{array}$ & 51413331 & 61462895 & 10049564 & 119,55 \\
\hline $\begin{array}{l}\text { Количество кредитов приходящихся на юриди- } \\
\text { ческих лиц и индивидуальных предпринимате- } \\
\text { лей - всего, ед. }\end{array}$ & 1,20 & 1,17 & $-0,03$ & 97,64 \\
\hline Юридические лица, получившие кредит, доля & 1,27 & 1,22 & $-0,05$ & 96,11 \\
\hline $\begin{array}{l}\text { Индивидуальные предприниматели, получившие } \\
\text { кредит, доля }\end{array}$ & 1,08 & 1,09 & 0,01 & 101,01 \\
\hline $\begin{array}{l}\text { Объем кредитов на } 1 \text { юридическое лицо и ин- } \\
\text { дивидуального предпринимателя получивших } \\
\text { кредит, млн. руб. }\end{array}$ & 44,55 & 32,55 & $-12,01$ & 73,05 \\
\hline
\end{tabular}

По данным исследования Экспертного центра при Уполномоченном при Президенте РФ по защите прав предпринимателей, в 2020 году основную массу кредитных заявок предприниматели подавали в рамках участия в программах «антикризисного» льготного кредитования и на реструктуризацию выданных ранее займов. В «докризисный» период (2018 год) свыше 60\% российских банков предлагали юридическим лицам программы кредитования для развития бизнеса. В частности действовали программы кредитования, такие как инвестиционные, коммерческая ипотека, факторинг и лизинг и прочеe.

Учитывая выше изложенное, видим, что Российский бизнес продолжает активно привлекать кредитные ресурсы. Хозяйствующие субъекты должны понимать, что привлекая по данным Банка России по состоянию на начало 01 января 2021 года общая сумма задолженности по кредитам, предоставленным юридическим лицам резидентам и индивидуальным предпринимателям составляет 30610 619млн. руб., в том числе просроченная задолженность 2156621 млн. руб. или 7,05\% от общей суммы задолженности.
Отсюда следует, что банки и иные кредитные организации, предоставляя экономическому субъекту финансовые ресурсы на условиях возвратности, срочности, платности должны быть уверены в кредитоспособности заемщика. Компании, испытывающие потребность в привлечении кредита должны экономически обосновать способность своевременного возврата кредитору взятых финансовых ресурсов с уплатой процентов в установленные сроки за счет собственных ресурсов.

Показатели финансовой устойчивости имеют большое информационное значение при принятии решений стейкхолдерами на стадии разработки бизнес-планов, определении стратегического развития компании, принятии решения о техническом перевооружении и прочее.

Одним из условий, при принятии решения о кредитовании бизнеса на инвестиционные цели деятельности является ликвидность и рентабельность бизнеса. Методика оценки заемщика предполагает оценку его финансовой устойчивости, в том числе соотношение собственного и заемного капитала.

При оценке финансовой устойчивости 
экономического субъекта оценивается в пер- демонстрирует возможность экономическоспективе эффективность использования его го субъекта успешно работать, рассказывает о привлечённого капитала при фактическом от- потенциале его развития, позволяет сохранить сутствии собственных средств (кредитное пле- баланс активов и пассивов в быстро изменячо). При грамотном использовании заемного капитала достигается прирост прибыли. ющейся среде и удерживать должный уровень

В целом, анализ финансовой устойчивости

\section{Библиографический список}

1. Банк России [Электронный ресурс] - Режим доступа._URL: https://cbr.ru/statistics/bank_sector/sors/ (дата обращения 25.03.2021).

2. Ким А. В. Влияние кредитной политики на финансовую устойчивость предприятия / А. В. Ким.- Текст: непосредственный // Молодой ученый. - 2018. - № 25 (211). - С. 68-70. [Электронный ресурс] - Режим доступа.-URL: https://moluch.ru/archive/211/51699/ (дата обращения: 26.03.2021).

3. ФНС России [Электронный ресурс] - Режим доступа.- URL: http://www.nalog.ru/rn77/taxation/reference work/conception_vnp/ (датаобращения: 26.03.2021).

4. Шеремет А.Д. Теория экономической анализа / Шеремет А. Д..- М.: Инфра-М, 2002.- 331 с. 